\title{
Leonardo da Vinci (1452-1519) and his depictions of the human spine
}

\author{
Garvin Bowen $^{1}$ - Jocelyn Gonzales ${ }^{2}$ (D) - Joe Iwanaga ${ }^{2}$ - Christian Fisahn ${ }^{2,3}$. \\ Marios Loukas $^{1} \cdot \operatorname{Rod}$ J. Oskouian ${ }^{2,3} \cdot$ R. Shane Tubbs ${ }^{1,2}$
}

Received: 19 January 2017 / Accepted: 30 January 2017 / Published online: 10 March 2017

(C) Springer-Verlag Berlin Heidelberg 2017

\begin{abstract}
Introduction Few individuals in history have exerted so great an influence and made such extensive contributions to so many disciplines as Leonardo da Vinci. Da Vinci's inquisitive, experimental mentality led him to many discoveries, such as spinal cord function and the proper anatomy of several organ systems. Respected not only as an artist but also as an anatomist, he made many significant contributions to the field. Conclusions This article explores da Vinci's drawings, in relation to the anatomy of the human spine.
\end{abstract}

Keywords History $\cdot$ Italy $\cdot$ Vertebral column $\cdot$ Spinal . Anatomy $\cdot$ Art

\section{Introduction}

Leonardo da Vinci, undoubtedly a visionary and pioneer in several disciplines [1-3], is respected as one of the greatest contributors to anatomy. This brilliant mind's resilience is demonstrated when one considers his humble beginnings. He was born in 1452 in Vinci, a country village on Mount Albano, within the valley of the River Arno, which divides Florence from Pisa. Although he was not taught Greek or Latin, which handicapped his attempts

Jocelyn Gonzales

gonzaj6@uw.edu

1 Department of Anatomical Sciences, St. George's University, True Blue, Grenada

2 Seattle Science Foundation, 550 17th Ave James Tower \#600, Seattle, WA 98122, USA

3 Neuroscience Institute, Swedish Medical Center, Seattle, WA 98122, USA to associate with the scholars of Florence at the time, he excelled in several fields of study. Giorgio Vasari, a well-known biographer of Leonardo, clearly depicts these sentiments in his statements about the youth:

"In arithmetic, during the few months he studied it, he made such progress that he frequently confounded his master by raising doubts and difficulties. He devoted some time to music and soon learned to play the lyre, and being filled with a lofty and delicate spirit he could sing and improvise divinely on it. Yet though he studied so many different things he never neglected drawing and working in relief, these being the things which appealed to his fancy more than any other [4]."

He demonstrated a keen desire to know, to explore, to attain the greatest heights of knowledge, and to reach his own conclusions regarding the true nature of any topic of discussion [5]. His untamed desire is expressed in his parting statement:

"I have offended God and mankind because my work did not reach the quality it should have [4]."

It was this lofty aspiration that set him apart from his contemporaries who, rather than possessing the spirit of inquiry that is necessary for scientific progress, were content to hold dogmatically to the views of their predecessors [6, 7]. As a youth, Leonardo became a trainee in topographical anatomy under the famous sculptor, Andrea del Verrocchio, to whose charge he was committed $[4,6,8]$. Once acquired, this skill would not only set his brilliant mind apart from his peers as an anatomist but would also make his work far superior to theirs and ahead of its time. Leonardo da Vinci's most perceptive work in anatomy began after his first dissection of a cadaver belonging to a 100-year-old female, whom he had recently witnessed dying. 


\section{Contributions to anatomy}

Amongst Leonardo's many contributions to anatomy were the first correct portrayal of the anterior and middle meningeal arteries and the anterior, middle, and posterior cranial fossae [9-11]. Other advances credited to him include accurately describing the heart as a four-chambered muscular structure, in an era when it was dogmatically viewed as two-chambered [4]. He even described the anatomical changes related to the pathophysiologies of arteriosclerosis, cirrhosis, and portal hypertension [4, 12]. His revolutionary approach to depicting anatomical structures presaged the concept of viewing anatomy not just topographically but from multiple angles and in cross-section, revealing deeper structures [4, 13]. This concept is commonly employed in medical anatomy textbooks and can be seen as the mainstay of education in medical anatomy today. His depictions demonstrated structures not only in relation to other structures but also in connection with their respective functions. Finally, the first accurate representation of the spine has been credited to Leonardo [14, 15], a topic to which we will return later in this article.

Although Leonardo's depictions were far ahead of their time, they were not all anatomically accurate $[4,12,16]$. This could be attributed in part to Leonardo's views being influenced to some extent by the concepts of his predecessors or a progression in understanding that occurred over time [6, 13]. His earliest dissection specimens were animals (namely horses, birds, oxen, and bears [12]), from which inferred human anatomy. It is plausible that some of the discrepancies in his earlier depictions are attributable to this.

\section{Depictions of the spine}

Although da Vinci's works in anatomy encompass the entire human form, this article's focus will now be on his treatise relating particularly to spinal anatomy. He was interested in the structure and function of the spine and was the first anatomist to delineate accurately the S-shaped structure (lumbar lordosis and thoracic kyphosis) of the human spine and the anatomical structure of the vertebral bodies with their proper articulations [17, 18].

Related to the spinal column, Leonardo revealed the function of the spinal cord in his novel experiments on frogs when he "pithed" them (pierced or severed the spinal cord, resulting in what he thought to be the death or immobilization of the specimen [6, 17, 19]). From this he deduced that the spinal cord was involved in control of movement and to some degree modulated bodily function. Reflecting on the outcome of his experiment he wrote:

'The frog instantly dies when the medulla of the spine is perforated; and previously it lived without head, without

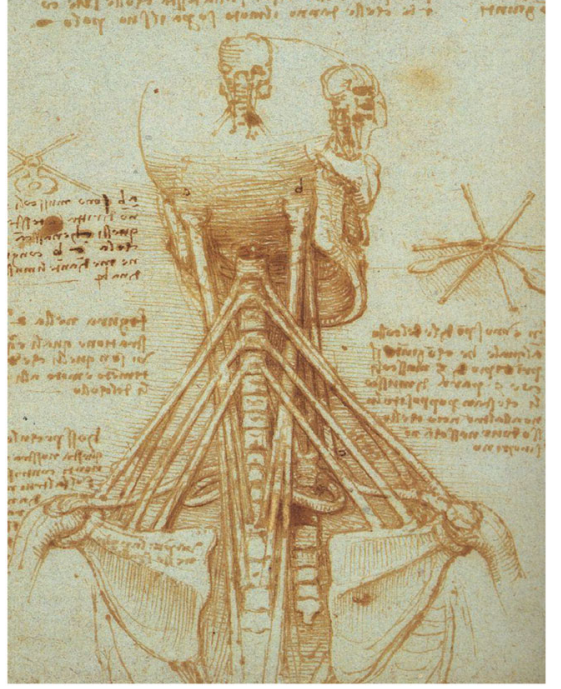

Fig. 1 and cover image Posterior view of the cervicothoracic spine with various attached muscles. The long muscle bands attaching to the mastoid process might represent the longissimus capitus. The other fibers arising from the spine of the scapula probably represent the upper fibers of the trapezius muscle but fall short of this muscle's cranial attachment onto the occiput. Note the small and block-like nature of the vertebrae

heart or internal intestines or skin. Here therefore appears to lie the foundation of movement and life [14]'.

Regarding da Vinci's depictions of the spine, many examples are available from extant sources. Fig. 1 and cover image depicts one of Leonardo's early illustrations of the spine. No muscles exist that attach the spinal column to the superior aspect of the scapula, or from the mastoid processes to the thoracic spine. Leonardo here seems to have been trying to

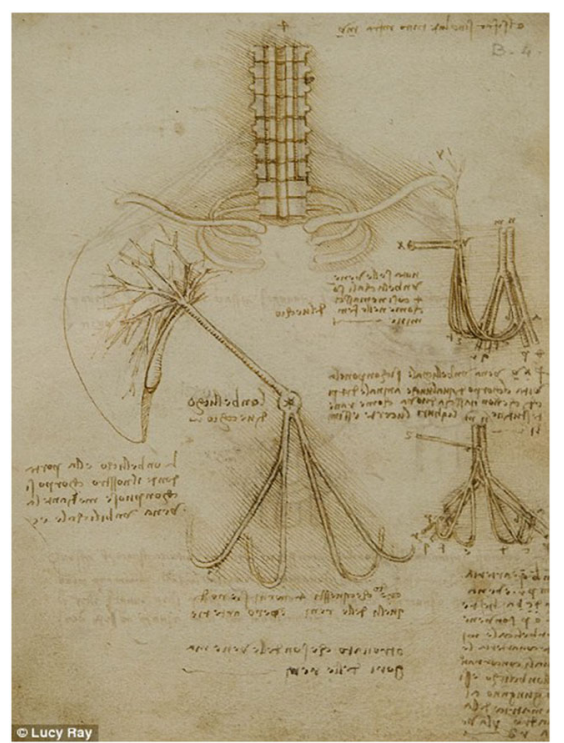

Fig. 2 Anterior view of the cervical spine and upper thoracic vertebrae (upper image). Note the similarity between vertebrae and their block-like nature 


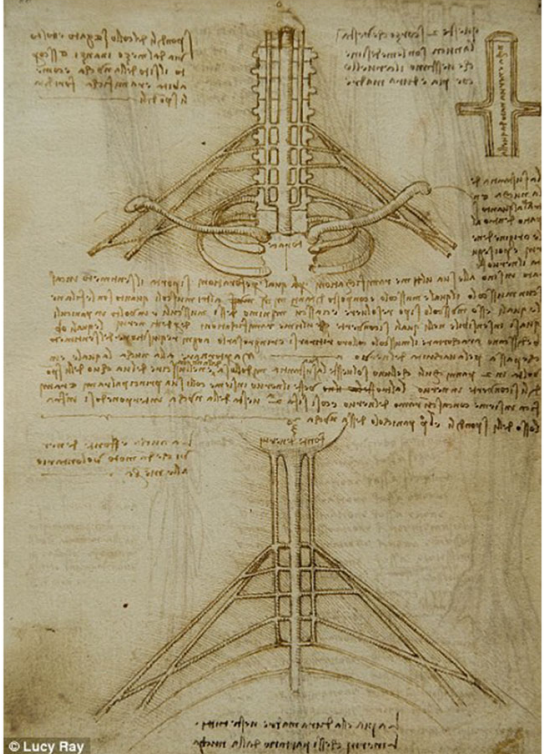

Fig. 3 Similar drawing to that seen in Fig. 2. The vertebrae are all of the same shape. Note the relationship to the exiting nerve roots contributing to the brachial plexus

depict the fibers of the trapezius and potentially some of the levator scapulae muscles. He may have used his knowledge of engineering to devise a concept that would functionally fit the movements of which the cervical spine is capable rather than trying to illustrate the exact anatomical detail. The vertebrae are portrayed in a rudimentary manner, many lacking a foramen to convey the neurovascular supply, an intervertebral disc, or the spinous process necessary for muscular insertion and rib articulation in the thoracic spine. It may be better to view this depiction as a conceptual illustration of how the structure accommodates its function. da Vinci seems to allude to this in a statement he made about this depiction:

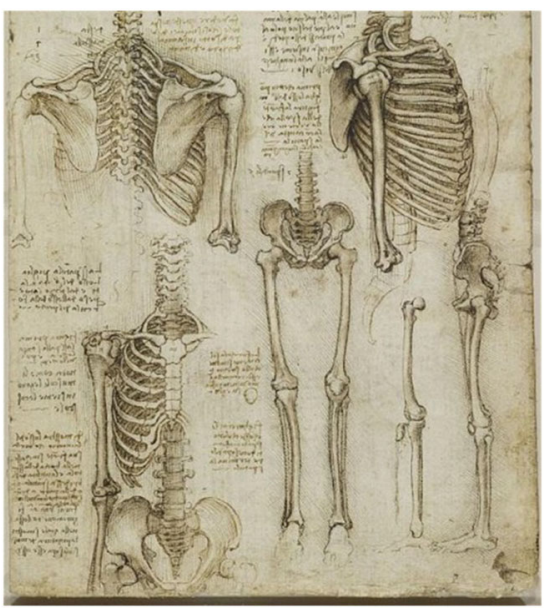

Fig. 4 Anterior and posterior views of the vertebral column. Although more details are added to this depiction, the overall anatomical detail of the spine is lacking

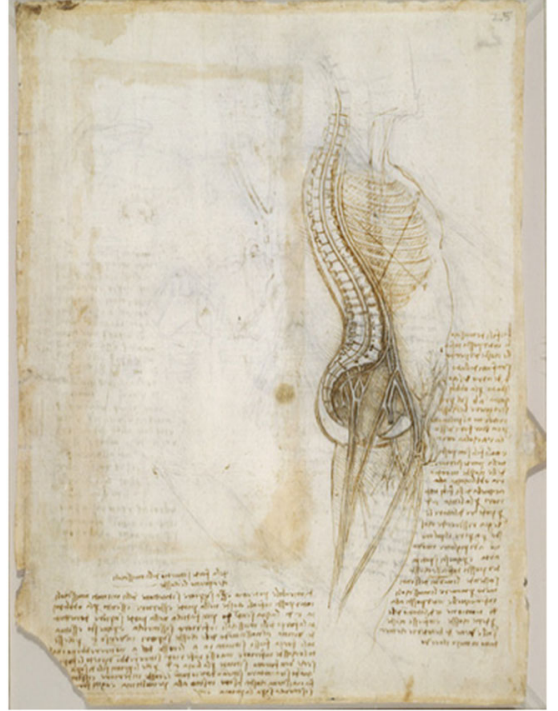

Fig. 5 Sagittal view of the spine noting the natural curvatures as seen by da Vinci. The overall detail of the vertebrae is elementary in nature

'You will first make the spine of the neck with its tendons like the mast of a ship with its side-riggings, this being without the head. Then make the head with its tendon which gives it its movement on its fulcrum' [4, $17,20]$.

Although the exact date when he drew this work of art is not known, one can assume that it was prior to any dissection of the anatomical region in question. This is because there are clear inaccuracies in his illustration. Given his attention to fine detail, this is most likely to be attributable to the aforementioned assumption.

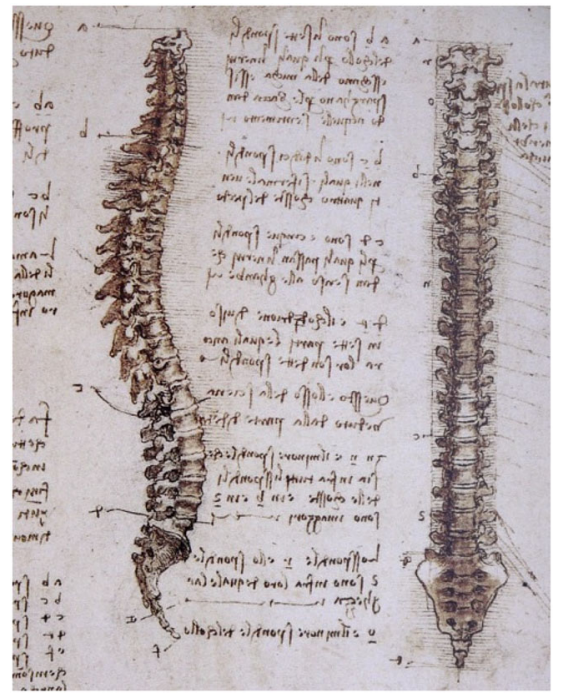

Fig. 6 Later drawing of the lateral spine. Compare to Fig. 5. Here the details of the finer anatomy of the vertebrae are apparent 
Similarly, Figs. 2 and 3 portray the vertebrae in an elementary fashion. Both seek to demonstrate a coronal section of the cervical spine. Within this section of the vertebrae we can see the spinal cord. However, they both lack many of the distinctive features of this structure that can be perceived at this level, such as the dorsal and ventral roots converging onto the spinal cord.

In clear contrast, Fig. 4 illustrates all of the anatomical features that can be appreciated from a posterior aspect, which were absent from Fig. 3. This being said, there are still gross inaccuracies. The inferior angulation of articulation of the ribs posteriorly is grossly exaggerated. Also, although the structure of the vertebrae approaches its true form, it is proportionally imprecise. Additionally, the 11th and 12th rib pairs are depicted as 'true ribs' instead of 'false ribs'.

In Fig. 5, da Vinci illustrates the sigmoidal curvature of the vertebral column. However, the drawing depicts the spinal column as being disjointed from the thoracic cage. This is corrected in Fig. 6, where he replicates the articulations of the vertebrae and structural dimensions of the vertebrae with great exactitude. This gives credence to the perception of Leonardo as an exceptional artist. Despite the absence of high-definition imaging modalities he was able to delineate the vertebral column's structure so accurately and precisely.

\section{Conclusions}

We can see a clear progression in terms of the accuracy with which da Vinci's anatomical drawings were developed and how his drawings were influenced by his mindset, not just as an anatomist but also as an engineer and scientist; and to some extent, by the prevailing scholastic views at that time. His anatomical depictions were clearly far ahead of their era and have served to improve our understanding of the true anatomy and function of the vertebral column and spinal cord.

\section{Compliance with ethical standards}

Conflict of interest The authors have no conflicts of interest.

\section{References}

1. Clark, K. (1988) Leonardo da Vinci, Penguin

2. Kemp, M. (1981) Leonardo da Vinci: the Marvellous Works of Nature and Man, Harvard University Press

3. Keele, K.D. (1983) Leonardo da Vinci's Elements of the Science of Man. Academic Press

4. Jose AM (2001) Anatomy and Leonardo da Vinci. The Yale Journal of Biology and Medicine 74(3): 185-195

5. O'Malley CD (1983) Leonardo on the human body. Dover, New York

6. Pevsner J (2002) Leonardo da Vinci's contributions to neuroscience. Trends Neurosci 25:217-220

7. Singer, C. (1975) In: Singer C (ed) Studies in the history and method of science. pp. 79-164, Arno Press

8. Bay NSY, Bay BH (2010) Da Vinci's anatomy. J Morphol Sci 27: 11-13

9. O’Malley CD, Saunders J B de C M (1952) Leonardo da Vinci on the Human Body, plate 6, Henry Schuman

10. Clayton, M. and Philo, R. (1992) In: Leonardo da Vinci: the Anatomy of Man, pp. 36-37, Bulfinch Press

11. Leonardo da Vinci (1978-1980) Corpus of the Anatomical Studies in the Collection of Her Majesty, the Queen, at Windsor Castle (Clark, K. and Pedretti, C. eds.), 42 recto, Harcourt Brace Jovanovich

12. Jones R (2012) Leonardo da Vinci: anatomist. Br J Gen Pract 62(599):319. doi:10.3399/bjgp12X649241

13. Mavrodi A, Paraskevas G (2013) Evolution of the paranasal sinuses' anatomy through the ages. Anatomy \& Cell Biology 46(4): 235-238. doi:10.5115/acb.2013.46.4.235

14. Bentivoglio M, Mazzarello P (2010) The anatomical foundations of clinical neurology. In: Handbook of Clinical Neurology 95: 149-168

15. Banerji R. (2012). Leonardo da Vinci: how accurate were his anatomy drawings? Retrieved July 13, 2016, from http://www.bbc.com/ news/magazine-17907305

16. Clayton L, Philo R (2012) Leonardo da Vinci, anatomist. Royal Collection Publications, London

17. Nanda A, Khan IS, Apuzzo ML (2016) Renaissance Neurosurgery: Italy's Iconic Contributions. World Neurosurgery 87:647-655

18. Naderi S, Andalkar N, Benzel EC (2007) History of spine biomechanics: part II-from the Renaissance to the 20th century. Neurosurgery 60:392-403 discussion: 403-404

19. Keele KD, Pedretti C (1978) Corpus of the anatomical studies in the collection of her majesty the queen at Windsor Castle. Vol. 1e2. Johnson Reprint Co., London

20. McMurrich PJ (1940) LeonardodaVinci-the anatomist. Williams and Wilkins, Baltimore 